\title{
THE PSYCHOLOGICAL PLAUSIBILITY OF RELIGIOUS FICTIONALISM
}

\begin{abstract}
In this paper I explain the psychological plausibility of religious fictionalism by finding the proper form of fiction that is analogous in relevant aspects to religious practice. First I examine the forms of fiction that are commonly listed in literature and explain why participating in these forms does not resemble taking part in religious community. After that, I establish characteristics of religious practice that the appropriate form of fiction would have to share, and find that acting shares most of these features. However, I argue that acting is still significantly different in some aspects, and propose the method acting as practiced by Daniel Day-Lewis as the only form of fiction that is analogous in all relevant facets. Then, by exploring how a method actor relates to the objects of the fictional world and to the real objects that do not belong to that world, and by finding similarities in his method and in religious fictionalism, I explain how the religious fictionalist differs from the realist in the content of his belief. I also use this analogy to explain the motivation for being a religious fictionalist: namely, to still be able to participate in religious practice because we find something worthy in it, although some doctrines of religion directly contradict the facts of science and our moral ideals.
\end{abstract}

Key words: religious fictionalism; psychology; religion

Religious fictionalism is often defined in opposition to religious realism and religious positivism. Religious realism interprets statements of religion as either true or false statements about transcendental reality ${ }^{1}$. A believer claims that these statements are most probably true while an atheist claims that these statements are most probably false ${ }^{2}$. The religious positivist interprets statements of religion as either true or false, not about transcendental reality but about our moral and spiritual lives (LePoidevin 1996, 112). Religious fictionalism does not interpret statements of religion as either true or false, but as useful fictions ${ }^{3}$ for

1 Or even physical reality, if pantheism is an option.

2 Here, I assume that both believer and atheist are in a certain sense epistemically modest, and that they do not know with absolute certainty that there is God. Most rational people would leave an open possibility that they could be mistaken about beliefs so complex like religious ones.

3 Fictions can still be either true or false (it is possible that Lord of the Rings, for example, describes some real state of affairs in a galaxy far away), but are taken to be highly improbable, and most significantly, their probability is not important for the role they play. 
providing moral guidance and bringing people together. Although the entire religion is understood as fiction, it is supposed to be the kind of fiction that is so powerful that it could produce deep emotions, function as social glue that binds people together, and guide moral lives of entire communities.

One common objection to religious fictionalism is that it is psychologically implausible (LePoidevin 1996, 112 and Eshelman 2005, 190). How could people celebrate Christ's resurrection if there was no Biblical Christ after all? How could people fall on their knees and give their entire being to the Lord if they believe there is no God? How could they pray if nobody is listening? How can the Ten Commandments motivate our moral lives when we know that they are just a part of tradition that existed a long time ago, and that was, according to our common modern judgment, racist, misogynic, and had a very strict social stratification?

It is important to correctly understand what the focus of this objection is. It does not say that it would not be useful to practice religion, once we understand its statements as fiction. It does not deny that faith understood this way can promote moral values or bind people together. What it says is that engaging in religious practice seems psychologically implausible once we interpret statements of religion as fiction. It would take some really strange psychological state for somebody to pray to God that is not real. Possibly an act of self-deception (Eshelman 2005, 193) or even some kind of madness.

An analogy with our enjoyment of the usual forms of fiction is often made to explain and to motivate the plausibility of religious fictionalism. There is nothing strange in people having deep emotions about something that they consider not to be real. The "red wedding" scene in Game of Thrones caused numerous people to weep and yet hardly any of them thought that Rob and Catelyn Stark where real people. The actions of the elder Zosima from Brothers Karamazov morally transformed many people, but hardly any of them believed that he was a real person. Fiction is a powerful medium that can greatly influence all kinds of persons and there is nothing psychologically strange about it.

In this paper I will inquire as to what is the form of fiction most analogous with religious practice, and how far this analogy can be stretched. In the end, the psychological plausibility of religious fictionalism will depend on the answer to this question.

Comparison is often made between religion and the forms of fiction that we enjoy as observers. Thus, LePoidevin refers to Hitchcock's Psycho, Dickens' novels and TV soaps (LePoidevin 1996, 115, 119). Eshelman is more careful here, but he still talks about experience of watching a play (Eshelman 2005, 193). Nonetheless, as these authors sometimes notice, this parallel falls short in one important aspect. Religion is a practice, and requires our participation, but our enjoyment of, say, reading a book and watching a film is of a different form; when we watch The Master or Casablanca we experience emotions as if that fictional world is real but we do not act as if it is real. We are always aware of the boundaries of that world, whether they are the edges of a TV or a projector screen. Even when there is a live recreation of the fictional world, as it is in theater plays or operas, we do not act as if that fictional world is actually there. If 
we rushed on to save Romeo and Juliet from committing suicide, people would say that we misunderstand what theatre is about. Our presence in that world is like the presence of an eye/mind which is able to see parts of the world that the author wants us to see, but which cannot interact causally with.

However, when we engage with religious material, our attitude is clearly different. We interact with God when we pray to him and we celebrate Easter with people that share our beliefs. We are part of a community that participates in a fictional world, not just observers of it. As Eshelmans puts it

/.../ the fictionalist view/.../ requires not simply that one be moved by a theistic narrative but to take part in the fiction through rule-governed ritual behaviors. In other words, the analogy here is not that of viewing a play but of being in the play and following the script (Ibid., 193).

Therefore, our participation is fundamental for our engagement in religious practice.

Although Eshelman mentions the analogy with acting in plays, he quickly moves on to the analogy with sport preparation, which, because it lacks the emotional and moral aspects, is not similar enough to a religious practice. LePoidevin also mentions an analogy that includes activity - children playing a game of make-believe together (LePoidevin 1996, 116) - but then, because such an analogy includes only quasi emotions and lacks duration he moves on back to TV soaps (Ibid., 121). Both of them do not develop analogies which involve active participation enough to encompass all of the relevant elements of religious practice. I will try to do that in the rest of this paper. However, first we must establish conditions which determine something as a genuine religious practice, conditions that any fictionalism we are looking for has to meet.

Genuine religious practice has to:

1.) involve participation - we have to be part of that (fictional or real) world.

2.) excite genuine emotions ${ }^{4}$ - It cannot resemble something like a children's make-believe game because a child wouldn't play a game of running from a monster if her fear was the same as fear of an actual monster.

3.) be pervasive, long-lasting and continuous, occupying a significant place in our lives. ${ }^{5}$

4 Genuine emotions could be loosely defined as emotions that have the same strength as the typical manifestations of these emotions. A child that is pretending to run from a tiger usually does not have genuine emotions, because she knows that there is no tiger there, and that there is nothing really to fear about. Her fear is fear "light".

5 One possible objection to this list is that it sets extremely strict criteria for something to qualify as a religious practice. However, I insist on it, because I want to explore whether religious fictionalism can replace deep and powerful religious practice of the realists, not be some kind of religion "light". The other possible objection is that the religious practice does not have to involve any emotions. That is, the relation with God and the religious practice could be entirely based on the rational reasoning and respect for the higher power. However, 
The element of duration is especially hard to capture, because our involvement with fiction is often periodical and it doesn't last more than few hours. But religion, even fictional, should be constant although practice itself isn't. LePoidevin tries to capture the element of duration with TV soaps, saying that they last for a long time (in terms of episodes) and occupy a significant percentage of our thoughts (LePoidevin 1996, 121). But that analogy is still problematic because enjoying TV soaps is not participation-based and is not continuous. An analogy with acting in plays that Eshelman makes is the best candidate, but it still obviously lacks duration and the question of quasi emotions is still a legitimate one. It seems that there is no obvious form of fiction which shares all three properties that religious practice should have. This is the reason why these authors often change between different forms of fiction, depending on the property of religion that they discuss. However, in the end it seems that there is no proper enjoyment of fiction which is analogous to religious practice in all relevant aspects, and that religious fictionalism is therefore psychologically implausible.

Still, I think there is one curious form that has not yet been considered. I want to propose a strange practice of method acting popularized by Daniel Day-Lewis as a form of fiction similar in all relevant aspects. First I will briefly explain what makes ordinary practice of acting successful, and then expand it by introducing the idea of method acting.

In his "Understanding acting" Richard Horbny lists three crucial characteristics of good acting performance and two of those three concern us here. The first one is the ability to of an actor to relate with every object that belongs to the fictional world of the play (Horbny 1983, 28). An actor should be able to relate to props on the set as if they are actually the things they represent: to use a fake plastic gun as a genuine killing device, to turn away from a paper mask as if it were a real disfigured face of some freak. He should also be able to relate to the other actors as if they are those persons they play. The actor also ought to have the capacity to relate to imaginary beings of the world of the play. If he is just looking at the camera, with the cameraman and the director behind it, but he is supposed to see an approaching tiger, he should have a vivid representation of the beast in his imagination.

The second characteristic is the pursuit of the objectives (Ibid., 31). Almost every character of some fictional story has certain goals that he is chasing after and every last bit of an actor's behavior should be performed with those goals in his mind. Relating is not enough. It brings only spatial dimension of the fictional world. If an actor only holds a gun as if it is a real killing device, but without having a goal of stopping a villain and saving his beloved, his performance will be lacking. The goal directed behavior of an actor brings the temporal dimension to the fictional world of the play in question. He is not relating just to the real and imaginary parts of the fictional world around him, but also to what that

I do not think that this is a plausible view since the emotion of love plays very important role in all major religions. 
world has been, what it will be, and how he can bring about important changes in that fictional world.

We can see how this correlates to first characteristic of religious practice. Both relating and goal oriented behavior are crucial for genuine participation in the fictional universe. Indeed, good acting and religious practice must include both of them. When we apply these two rules to the behavior of religious fictionalist we will see that, for example, she has to relate to the bread and wine as if they are the holy relics of Jesus Christ. She should relate to the fictional God as if he is a real deity. But the fictional universe of religion must also have temporal dimension and her behavior has to be goal oriented. In prayer, she is praying for her goals to be realised in the future, and her religious practice is related, as far as her memory serves her well, with everything that she did in the past.

However, the question of genuine emotion and the problem of continuity still remain. Actors leave the fictional world once that play is over or that camera stops shooting, and they return to normal life. They might be still emotionally attached to that world but the prop gun is now just a prop, and his goal is not the goal of the character that he is playing but of his own goal. As Hornby said: "It is important that an actor be sensitive and imaginative, but not that he be a lunatic" (Horbny 1983, 28).

But what if the actor, in his attempt to reach the highest connection with the fictional world, behaves in a certain way that would resemble lunacy to an outsider? What if he didn't break a role for the whole duration of the shooting? That is the requirement of method acting, and one famous actor - Daniel DayLewis brought that method to the extreme. In My Left Foot (1989), Day-Lewis spent eight weeks at a cerebral palsy clinic in Dublin, learning to speak as the character he played spoke, and to write and paint with his left foot, as his character did. He famously said that: "films don't begin only when the camera starts rolling". During the whole process of filming he stayed in character at all times, never leaving his wheelchair. He was lifted into and out of the car that brought him to filming, and over the cables that littered the set, and was fed by members of the crew (The Telegraph 2013). While playing Hawkeye in The Last of the Mohicans, Day-Lewis learned how to capture and skin animals, construct canoes, battle with tomahawk axes and shoot a 12-pound flintlock while running. Day-Lewis insisted on carrying his gun wherever he went, even bringing it to lunch with his family on Christmas day. When Day-Lewis completed filming, he suffered from hallucinations and claustrophobia; "I've no idea how not to be Hawkeye", he told to the director (Ibid.). He had a similar approach to many of his other films, like There Will Be Blood, Gangs of New York, and Lincoln.

This approach to fiction has the element of the continuity that religious practice requires. It is also all-encompassing, occupying the entire actor's life during the shooting. Concerning the question of quasi-emotions, I would claim that method acting produces emotion as strong as they can be when produced by fiction and clearly as strong as emotions produced by real events of that kind. However, I am not a method actor, and perhaps the levels of the emotions in questions are so nuanced that only they could tell us the truth. 
Therefore, it seems that there is a good analogy with fiction after all that can make religious fictionalism psychologically plausible. In the practice of method acting there are all three important properties of religious practice: engaging with the community that is related to the fictional world, feeling genuine emotions and participating in activity that is pervasive and continuous. The only problem for the analogy is the impact that advanced method acting has on the persons practicing it. Remember the word of Day-Lewis: "I've no idea how not to be Hawkeye". It could seem to an outsider that such deep and continuous engagement with some fictional world can temporarily erase the boundary between the fictional and the real. And since the shootings of the movies end after a few months or years, but religious practice last for a lifetime, interpreting fictionalism in a way similar to method acting could prove problematic for the very existence of that position. That is, according to this analogy, fictionalism would be psychologically plausible but it would dissolve into realism when applied to religion.

To determine whether this happens we need to fully understand how the method actor experiences the world during filmmaking. However, to be able to do that one has to have first person experience of method acting. Since I do not possess that kind of experience, as an alternative I am going to try to guess what happens based on my third person point of view.

It seems to me that any good method actor has two related but distinct abilities. The first one is to suspend his beliefs about fictional objects being unreal (I will call them contextual unreal objects). The second one is to suppress the beliefs about the existence of some real objects that do not belong to the context of fictional world (I will call them non-contextual real objects). Concerning the former, he is able to interpret, say, fictional character's motives as real motives and a prop sword as a real sword. Concerning the later, he is still aware of the camera and the microphone that follow him throughout the shooting and he stills listens to a director for the instructions between the scenes, but at the same he is not fully conscious of them. He is like a person who is driving a car, which concentrates on the road ahead, but does not pay immediate attention to it.

It is important to notice that, if my interpretation of his world is correct, it follows that his experience is not the same as that of the realist. This is because their beliefs have different content. Although it could be argued that his attitude towards contextual unreal objects is such that during his highest focus of method acting he actually perceives them as real, it would be implausible to claim that he isn't aware at all of non-contextual real objects like the camera, the script, the director, the lighting and so on. His awareness is not full, but it is still some kind of awareness. Thus, this form of fictionalism in method acting does not dissolve into realism.

Now we need to inquire if the same happens when this form of fictionalism is applied to religion. If something corresponding to the non-contextual real objects exist in the religious practice of the fictionalist, then interpreting fictionalism as analogous to method acting would not lead to the merging of the religious fictionalism and realism. At the first glance in the world of the religious 
fictionalist there are no objects similar to the non-contextual real objects. By the presupposition of religion the entire universe was created by God, and thus everything that exists belongs to the world of fiction. However, for many fictionalists there are actually some objects that do not belong to that world of religion and these are the facts of science and moral ideals that directly contradict the religious doctrine. Theory of the evolution, with the fossil and geological records supporting it, would be an example of these facts that contradict the idea that man is somehow special and divine, and that he was made by God to be radically different from other animals. Some parts of physics, like celestial mechanics would contradict the idea that the world was built according to the well-thought design of the divine creator. The belief that animal sacrifice is morally wrong would be the example of the other kind. That belief would be put aside when a religious fictionalist celebrates that God send an ox to Abraham to sacrifice instead of his son (Genesis 22).

If the religious fictionalist accepts these scientific theories and moral ideals, his relation towards them during strong religious focus would be similar to that of the method actor to non-contextual real objects. Specifically, he would still believe that those theories are true and the ideals correct, but he would suppress that during the religious practice. Therefore, it seems that there is a strong correlation between the fictionalism in method acting and the religious fictionalism, and the later does not become religious realism if we apply the analogy.

Although the final stage of this argument may seem odd, I think that it plays the perfect part for most of the religious fictionalists, since it appears to me that the motivation behind this theory is to find a form of the religion that can incorporate the changes that happened in science and in our moral judgment during last five centuries.

\section{Conclusion}

This analysis has led us to the understanding of how religious fictionalism can be psychologically plausible. It turned out that for something to qualify as a religious practice, it had to meet rather strict criteria concerning involvement and dedication, and that the only practice related to fiction which fulfills these criteria is the kind of method acting championed by Daniel Day-Lewis. The fact that this is the only proper analogy shed some vital light on the distinction between religious fictionalism and realism, and, in the end, uncovered the link between the motivation for religious fictionalism and its psychological plausibility. It seems to me that the educated and liberal person is the one who chooses religious fictionalism over realism because she sees something valuable in religion, but she cannot interpret religion as a realist because that contradicts her worldview. Despite this she can still participate in the religious practice, relate to the objects and people of that practice, and suppress her belief in facts of science and moral ideals in the same way that a method actor does in order to relate to the fictional universe during filming. This shows us that it 
is psychologically possible to participate in the complex and demanding world of religion and still be fictionalist about it. From the great proponents of the method acting - primarily Daniel Day-Lewis - we can learn more about how that could be done.

\section{References:}

Eshelman, Andrew S. 2005. "Can an Atheist Believe in God?" Religious Studies 41(2): 183-199. doi: 10.1017/S0034412505007602

Horbny, Richard. 1983. "Understanding Acting." Journal of Aesthetic Education 17(3): 19-37.

LePoidevin, Robin. 1996. Arguing for Atheism. London and New York: Routledge. The Telegraph. 2013. “The Method Madness of Daniel Day-Lewis." The Telegraph, Jan 23. http://www.telegraph.co.uk/culture/culturepicturegalleries/9819469/ The-Method-Madness-of-Daniel-Day-Lewis.html?frame $=2459178$ 